\title{
CIUDADANÍA INTERCULTURAL: DIVERSIDAD, DIFERENCIAS, TOLERANCIA Y PAZ
}

\section{INTERCULTURAL CITIZENSHIP: DIVERSITY, DIFFERENCES, TOLERANCE AND PEACE}

\section{AUTORA \\ Carmen Aranguren Rincón \\ Universidad de los Andes. Mérida-Venezuela (Venezuela). \\ carmenaran@hotmail.com}

\section{RESUMEN}

El mundo actual se debate dentro de una problemática que afecta los diversos ámbitos de la vida planetaria; entre ellos la destrucción fratricida que empuja a la sociedad y la cultura hacia grados límites de violencia. El desconocimiento del Otro diverso conduce a obviar los modos distintos de pensar, sentir, actuar y disentir de las culturas y sus identidades múltiples. De aquí que la búsqueda de la paz, con sentido de convivencia humana, sea una constante preocupación para reconocernos en la alteridad social. Un punto clave de esta aspiración es aceptar la hibridación sociocultural en la construcción de la ciudadanía, con una visión pluralista que se afirme en el diálogo y la tolerancia, como nuevos modos de encontrarnos y resolver los conflictos que amenazan la coexistencia en el universo planetario. 
PALABRAS CLAVE

Paz - Conflictos - Diversidad sociocultural - Convivencia.

\section{ABSTRACT}

The current world is debated within a problematic that affects the diverse areas of the planetary life; between them the fratricidal destruction that pushes to the company and the culture towards degrees limits of violence. The ignorance of diverse Other one drives to obviate the different ways of thinking, feeling, acting and dissenting from the cultures and his multiple identities. Hence that the search of the peace, with sense of human conviviality, is a constant worry to recognize ourselves in the social otherness. A key point of this aspiration is to accept the sociocultural hybridization in the construction of the citizenship, with a pluralist vision that steadies itself in the dialog and the tolerance, as new manners of finding and resolving the conflicts that threaten the coexistence in the universe.

\section{KEY WORLDS}

Peace - Conflicts - Sociocultural diversity - Conviviality 


\section{ÍNDICE}

1. Introducción

2. La idea de ciudadanía intercultural

3. El contexto actual y los valores

4. Interculturalismo y formación ciudadana

5. Escenarios y relaciones del interculturalismo

6. Ciudadanía y exclusión social

7. Teoría y práctica de la ciudadanía. Teoría y práctica. Modos de pensarla

8. Bibliografía

\section{Introducción}

Desde que el mundo es mundo los seres humanos, como grupos societales o actores individuales, han tratado de imponer la propia cultura a su oponente; algunas veces con violencia; otras, con persuasión o distintos modos de convencimiento. Ya, desde los tiempos bíblicos de Caín y Abel se manifiesta la destrucción fratricida que, salvando la distancia temporal, aún hoy conmueve a la humanidad.

Es cierto que vivimos entre culturas distintas que pudiéramos llamar el mundo pluricultural. En este universo los seres humanos, de una u otra manera, conviven 0 coexisten y aportan sus modos de pensar, sentir, actuar y disentir. Es, dentro de este intercambio donde se produce la hibridación cultural, que como vemos, se enriquece en 
la relación respetuosa hacia el Otro diverso, diferente. Ese Otro que permite reconocernos a nosotros mismos como criterio definitorio de existencia humana.

Nunca como en el presente, las sociedades han vivido la angustia de resolver este "antagonismo" aparente entre el ser yo y el ser nos-otros; en palabras distintas, entre el yo individual y el yo colectivo. Este ordenamiento propicia la aceptación de lo heterogéneo en el marco de la cultura occidental, asumiendo lo diverso como pluralismo cultural. Así, entonces, desde el renacimiento hasta la modernidad, el imaginario humano ha buscado explicaciones a las tendencias utópicas y a las racionalistas que juzgan la diversidad y la homogeneidad como esferas antagónicas, que involucran posturas encontradas.

Nuestro planteamiento busca pensar las relaciones interculturales, la ciudadanía y la Paz desde la comunicación, el diálogo y la tolerancia, entendidos como los nuevos modos de encontrarnos y estar juntos. Esto, permite la elaboración de un nuevo mapa que alcanza otro valor con significados distintos en sus saberes, relaciones, emociones y prácticas sociales, evitando los idealismos caducos, ajenos a la realidad histórico-social y a un modelo político que adquiere sustancia en un espacio y un tiempo determinados. En este sentido, la comunicación constituye un eje importante del interculturalismo, pues ella "se realiza de lo que hace pensar con sus palabras, objetos, estructuras, símbolos y de lo que hace sentir con sus imágenes, sentimientos, pasiones, significados"; (S. González. 2005:51); proceso dialógico en el cual se construyen actitudes, conocimientos y sensibilidades, en el entramado de la vida cotidiana. 


\section{La idea de ciudadanía intercultural}

El breve preámbulo anterior servirá de base para adentrarnos en el concepto de ciudadanía intercultural que implica, por definición, interacción y diálogo entre diversos actores y culturas, en base a principios éticos donde se reafirman la dignidad y el respeto hacia los diferentes modos de expresión cultural y sus patrones identitarios; entiéndase que todo sujeto-ciudadano se apropia de manera consciente e inconsciente de ellos, para reconstruir los significados culturales en un sistema político particular.

Indudablemente, que esto requiere de la formación del pensamiento crítico para entender la complejidad tangible y simbólica de las culturas.

De lo que si estamos seguros es de que toda cultura es vivida, transitada, habitada y pensada por los ciudadanos, quienes la contemplan o intervienen para "dejar pasar" o transformar su condición en las interrelaciones comunes. Como toda obra humana, la cultura es origen y producto de la acción colectiva de las generaciones sociales en el tiempo. Éstas, en su transitar por las calles, plazas, mercados, iglesias y demás lugares, van creando y recreando costumbres, tradiciones y opiniones que conforman, entre otras experiencias, la trama cultural comprometida con una lectura política de las redes del poder establecido.

El contexto sociocultural y la construcción de la ciudadanía constituyen un complejo proceso histórico que, desde la conflictividad y la contradicción, se enmarca en espacios de hibridación y mestizaje sociopolítico. Se trata de un sistema de valoraciones y de redes identitarias, afirmadas en el concepto de Nación asumido por un estado particular que fundamenta un conjunto de derechos. Este proceso apunta a la formación de un modelo de ciudadano, protagonista en el espacio público de socialización.

El escenario visible e invisible de la ciudadanía tiene su asiento en los múltiples entramados del sistema de relaciones y de convivencia social. Así, desde el habitar 


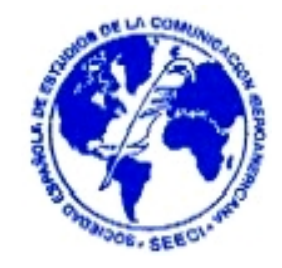

rutinario hasta los modos de imaginar que se traducen en comportamientos, se esparcen distintas percepciones y subjetividades propias de la cultura cívica. Este proceso de socialidad teje un conjunto de interacciones -algunas erráticas, otras estables- que configuran condiciones de vida excluyentes e inclusivas, de acuerdo a la prevalencia de intereses de la organización política y de los grupos de poder.

\section{El contexto actual y los valores}

Vivimos una época de extraordinarios cambios, donde la realidad sociocultural es cada vez más heterogénea y su marco fragmentado reclama una visión profunda sobre la participación ciudadana, particularmente en aquellos Estados donde algunos derechos constitucionales están en juego debido a la imposición de un modelo político, ajeno al bienestar nacional y al protagonismo social y público de la sociedad que demanda mejores condiciones de vida. En este contexto, la diversidad cultural provoca un descentramiento del sentido de pertenencia, de los conflictos sociales, de las tradiciones y la participación pública. No es extraño a esta situación, el vivir un exilio interior, marcado por el miedo a opinar y disentir del discurso oficial predominante. Esto, produce en la población sentimientos de impotencia que desembocan, muchas veces, en conductas conformistas y pasivas ante un poder consecuente con prácticas intimidatorias.

Los riesgos que involucran la construcción de una nueva ciudadanía, aún difusa, y el cruce de inminentes desajustes socioeconómicos y culturales, desplazan formas tradicionales de convivencia y de intercambio social, hacia prácticas inéditas y de confrontación en la lucha por el reconocimiento, que es el derecho a existir en la diversidad, aún cuando muchas veces los grupos excluidos se tornan pasivos y se refugian en el silencio voluntario o impuesto, en razón de la necesidad de sobrevivencia. 
REVISTA DE LA SEECI.

Aranguren Rincón, Carmen (2009): Ciudadanía Intercultural: Diversidad, diferencias, tolerancia y paz. No 19. Julio. Año XIII. Páginas: 117-133

ISSN: 1576-3420 DOI: http://dx.doi.org/10.15198/seeci.2009.19.117-133

La multiplicidad de sentidos ciudadanos transforma los modos de sentir, de percibir y de saber en el contexto real y simbólico de la colectividad, donde transitan representaciones de ciudadanía en continua mutación.

La tolerancia y la seguridad son valores que soportan la formación de la ciudadanía intercultural en una sociedad que propicie la justicia; no en vano es posible reconocer que "una inmensa mayoría de pobladores ha construido su forma de ser ciudadano en medio de profundas exclusiones sociales, económicas y políticas; de discriminaciones y estigmatizaciones como portadores de referentes culturales diversos" (G. Naranjo y otros, 2001:15). En este ámbito se incluyen grandes problemas que ponen en peligro la seguridad planetaria. Así, el aumento de la pobreza, las enfermedades, el exceso de población, la violencia, la carrera armamentista, la falta de viviendas, la delincuencia y el deterioro del ambiente natural, sólo podrían resolverse en un clima de entendimiento, de paz y de acuerdos nacionales e internacionales, donde se admita el valor de la vida humana por sobre cualquier otra prioridad. Todo esto, define las intersubjetividades y las demandas en procura de reivindicar la cohesión colectiva a través del aprendizaje de vivir juntos.

Con respecto a nuestro país, podemos decir que esta aspiración se destiñe en medio de los altos índices de violencia, inseguridad e impunidad jurídica, que padece la sociedad venezolana. ${ }^{1}$ Las cifras escandalosas de homicidios, secuestros, criminalidad y demás delitos, destruyen día a día la paz ciudadana y el derecho a vivir con sosiego, en la construcción de una sociedad más justa para una vida mejor. Cualquier proyecto que

\footnotetext{
${ }^{1}$ Según el CICPC, 44 venezolanos murieron cada día a manos del hampa durante el año 2009. Cifras extraoficiales de la Dirección de Estadística de la policía científica, señalan que el año 2009 cerró con 16.094 homicidios en Venezuela. En informe del Ministerio público del 2008 se expone que sólo el 6\% de los crímenes investigados llegan a juicio. Así vemos que la impunidad en el país es un problema que reviste gravedad. www. Google. Cifras de homicidios en Venezuela, lunes 8 de febrero de 2008. Publicado por Miguel Ángel González. Seguridad y prevención, blogspot.com / .../ Consulta el 31-10-2008.
} 


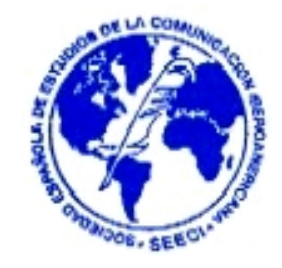

ignore la realidad señalada estará destinado al fracaso y a la pérdida de credibilidad en un sistema político que pretenda la búsqueda de equidad social. Por supuesto que la complejidad de esta situación exige una concertación de esfuerzos entre todos los actores y grupos que conforman el colectivo nacional, pues la contribución en cuanto a propuestas alternativas pudiera beneficiar un diseño de abordaje a la grave problemática.

Un caso al que podemos hacer referencia, relacionado con el señalamiento anterior, es la pérdida de libertad del ciudadano que por cuidar su vida y sus pertenencias traza itinerarios convenientes para su protección, pero muchas veces ajenos a sus necesidades cotidianas. A cualquier observador impresiona lo que pudiéramos llamar, en Venezuela, las "ciudades enrejadas", donde el cercado de las viviendas habla de temor e inseguridad, de carencia de paz. Esto, por supuesto, incide en la formación de una personalidad cautelosa o paranoica, por el riesgo permanente que fortalece una estética del miedo, generadora de frustración, donde el mundo exterior constituye una amenaza constante.

De hecho, el ciudadano soporta diariamente las consecuencias de vivir atemorizado ante el asalto imprevisto a su integridad física y emocional que altera la convivencia y el sentido de pertenencia en razón de una cultura desequilibrada. 


\section{Interculturalismo y formación ciudadana}

La presencia constante del interculturalismo en la formación ciudadana, reclama nuevas orientaciones con fundamentos que busquen la integración ${ }^{2}$ en la diversidad, en las identidades desplazadas y en el pluralismo. Se entiende que el marco territorial de la ciudadanía ha sido trastocado por el mundo globalizado, pero no puede perderse de vista la justificación de legítimos valores que obligan a proteger la libertad y las diferencias en lo que respecta a la superación de estereotipos culturales, provocadores de conductas excluyentes y etnocéntricas.

La persistencia de los procesos de hibridación cultural, en nuestras sociedades, conduce a la aceptación de la razón histórica de las culturas, lo que legitima la construcción de la identidad personal en relación con los otros y con las distintas maneras de percibir el mundo como patrimonio común, dentro de una visión pluralista y de responsabilidad compartida.

Algunos estudiosos consideran que en los grupos excluidos predomina una cultura frágil que reproduce un sistema de relaciones primarias; ideas que, indudablemente, destruyen las formas diversificadas de ciudadanía y niegan el papel de estos grupos en la articulación del orden social.

La exclusión sociopolítica ocasiona la angustia del desarraigo físico, emocional, social, económico y cultural. La realidad impredecible y el sentimiento de asumirse "ciudadano" de segunda o tercera categoría, invade la interioridad del excluido quien se percibe como un ser de ninguna parte, deslocalizado e inmerso en una otredad desde la cual se reconoce como individualidad anodina, sin posibilidad de narrar su historia que a nadie

\footnotetext{
${ }^{2}$ Nos referimos a la integración crítica como identidad colectiva, capaz de reconocer la diversidad sin que ello signifique pertenencia incondicional.
} 
interesa. Esta visión no significa siempre conformismo, desaparición o anomia, pues la fuerza de la resistencia constituye un acicate para posicionarse en otros espacios y desde allí, anunciar su voz y su presencia nómada en un constante rehacerse y reconfigurar el mapa de su intimidad perturbada.

El recorrido histórico de las sociedades muestra situaciones donde la hostilidad hacia lo diferente constituye causa de desintegración y exclusión, con lamentables saldos de injusticia y contiendas bélicas. Esta mirada convoca a formular nuevas preguntas y respuestas sobre la moral pública, lo que insta a la indagación acerca de cuál ciudadanía intercultural hablamos y cuál admitimos institucionalmente y, en nuestras prácticas habituales.

El interculturalismo es una cuestión de derechos que exige reivindicar a vastos sectores sociales para la coexistencia como actores públicos, desde las oportunidades que brinda el acceso a los beneficios de la modernización en una sociedad que pretenda la equidad. Por este medio se ha de garantizar el conocimiento, el diálogo y el respeto a las diferencias entre culturas, que significa también, distintos modos de pensar y practicar la ciudadanía.

Lejos de asumir una visión "culturalista", aceptamos la importancia de los procesos económicos, sociales y políticos que inciden en los cambios culturales, legitimados por la organización de una sociedad, basada generalmente, en la desigualdad y en los particularismos del poder ${ }^{3}$. Martín Barbero señala que "la cultura es el espacio de producción y recreación del sentido de lo social, donde el orden y los desórdenes sociales se vuelven significantes" (1987: 85). No obstante, desde una matriz de

\footnotetext{
3 Julio Caravana acepta que los problemas interculturales tienen, sobretodo, carácter intrasocietario. Para ampliar este criterio consultar Revista de Educación. No 302, págs. 61-82, 1993.
} 


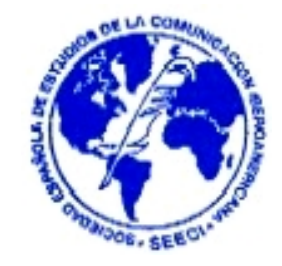

opciones y elecciones, es posible orientar la construcción de la ciudadanía intercultural, articulando igualdad y diferencia con el reconocimiento de las diversas identidades colectivas y la interrupción del fenómeno de la exclusión. Ahora bien, los problemas del interculturalismo y el multiculturalismo serán permanentes, mientras no se concreten en comportamientos cotidianos donde se implique la formación de valores cívicos y éticos, en un estado que legitime la igualdad de derechos ciudadanos.

\section{Escenarios y relaciones del interculturalismo}

Entendemos que las condiciones económicas, políticas y sociales comportan en sí un modelo de cultura; es decir, un modo de producir, reproducir, disfrutar, alcanzar 0 inalcanzar los bienes materiales e intangibles que circulan en la sociedad. El efecto de las desigualdades que padece gran parte de la población mundial, provoca una diáspora de colectivos humanos en búsqueda de "mejores" medios de vida. Esto, conlleva el trasplante de necesidades objetivas y subjetivas que encubren formas de socialización manifiestas en normas invisibles, experiencias, valores, creencias y prácticas, tejidas en un imaginario que se reconstruye en la confrontación con la "otra" cultura.

El problema del interculturalismo ha sido siempre objeto de dudas, conflictos y hasta determinismos, pues la misma organización de la sociedad y su sistema jurídico-político, establecen mecanismos de infravaloración de los excluidos o desplazados con base en la negación de sus derechos cívicos, marcada por el aislamiento que ocasiona la discriminación social; no obstante, estos grupos pugnan por ser aceptados como actores políticos y sociales en busca de legitimar su status de sujeto ${ }^{4}$ histórico en la diversidad

\footnotetext{
${ }^{4}$ Nos adscribimos al concepto de sujeto sostenido por R. Follari (2000: 85), quien lo asume como "sujeto dividido, que no se sabe a sí, que está hablado desde el Otro, que está atravesado por lo inconsciente (...) sujeto no atado en lo trascendental, sometido al flujo cambiante de las condiciones de lo real (...). Falible, diferenciado, cada vez con menos pretensión de sostener universalidad, objetividad, regularidad".
} 
social. De este modo, se pretende la afirmación identitaria que incluye la mirada del "otro"; pues las identidades no son construcciones inmóviles, universales o unívocas, sino entidades históricosociales mutantes, siempre abiertas al cambio y a la discusión.

En consecuencia, tanto el proyecto de vida como el sentido de pertenencia requieren de la dialéctica intercultural que implica, igualmente, el disenso y la alteridad en la construcción de una ciudadanía crítica, abierta a distintas experiencias, próximas 0 lejanas, a través de las cuales es posible insertarse en el mundo de nuevas complejidades como el que actualmente presenciamos.

Latinoamérica es un ejemplo del eterno transitar hacia la conformación de una sociedad civil que construye la esencia de ser ciudadano. En este trayecto enfrenta el reacomodo a las exigencias de la modernidad y a las contradicciones internas, generadas por los procesos de globalización y de mercado, con su influencia en las redes de socialización y de participación ciudadana donde se gestan los valores subjetivos.

Desafortunadamente, no resulta fácil la concreción de esta visión, por cuanto ello amerita un reconocimiento institucional de la legitimación política y social que dicta pautas "interesadas" desde el poder central, a la organización ciudadana. En un espacio más limitado y en consonancia con la idea anterior, San Martín Ramírez comenta que "los programas de educación ciudadana o cívica en América Latina tienden a reforzar una visión que se cierra en valores tales como el patriotismo, los símbolos o emblemas patrios, las figuras históricas y la sobrevaloración de lo distinto por sobre lo común" (2003: 90). 


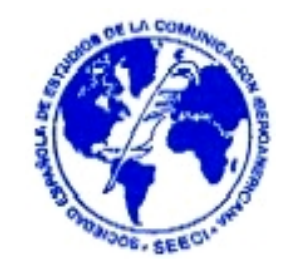

\section{Ciudadanía y exclusión social}

Es evidente que nuestros países carecen de una convicción ética que conceda prioridad a la formación de la conciencia ciudadana y a los valores de participación democrática, sustentados en una mejor calidad de vida. La negación de este derecho contribuye al crecimiento de grandes sectores de población excluida, de tal modo que éstos permanecen al margen de la ciudadanía plena y del empleo productivo. Todo parece indicar la necesidad de implementar políticas que garanticen el acceso ciudadano a un sistema global de oportunidades.

Este panorama remite a una crítica de la construcción de ciudadanía, falseada -en muchos casos- por la aspiración de proponer una referencia homogénea del proceso de identidad cultural, desvinculada de la multiplicidad de dinámicas que se crean, reproducen y transforman en las relaciones del sujeto colectivo con la realidad social. Es notorio que muchas veces los discursos políticos se inclinan por dividir a los actores sociales en "malos" y "buenos"; estos últimos con dotes extraordinarias, inalcanzables para el resto de los mortales, enfoque que legitima exclusiones y actitudes conformistas ante la comparación con supuestos héroes míticos.

En un orden de ideas complementarias, nos referimos a la circulación de discursos políticos construidos sobre la división entre nosotros/los otros, donde el nosotros se identifica con seres "perfectos e incólumes" y los "otros", con los enemigos a destruir. Desde esta perspectiva, se instituye un universo de significaciones, pautas morales y comportamientos reales y simbólicos que interactúan en el escenario social. Esta situación, por sus consecuencias, merece múltiples lecturas para descubrir los códigos transmitidos y fundamentados en evidencias o arbitrariedades. Desde el análisis de problemas sociales y sus transformaciones es posible dar un vuelco a estas posturas, que explican las condiciones concretas de la realidad en la que se producen. 


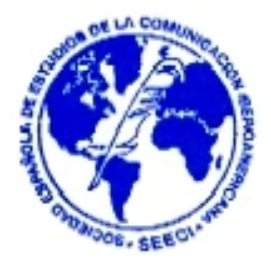

En sentido contrario a lo expuesto anteriormente, el estado y la sociedad tienen entre sus fines políticos, formar ciudadanos y preservar la memoria colectiva, sobre todo en nuestras sociedades que han hecho del olvido una razón de pérdida identitaria. Subrayamos que "la memoria es una construcción social (...). Su constitución y su resultado es debido a las prácticas humanas, fundamentalmente discursivas y comunicativas que son las que le confieren valor y significado" (F. Vázquez. 2001: 131). En este ámbito, hemos de aceptar que la producción humana, en cualquiera de sus expresiones, es también memoria acumulada que evidencia y oculta al mismo tiempo los trayectos de la ciudadanía.

El cambio epocal que transitamos admite una conciencia ciudadana intersubjetiva, que irrumpe en el paisaje estético de la existencia en búsqueda de una resignificación del espacio público-institucional y del mundo del trabajo en los procesos de segregación y mundialización.

\section{Teoría y práctica de la ciudadanía. teoría y práctica. modos de pensarla}

Entendemos que, sin una crítica epistemológica del discurso y de la práctica de la ciudadanía, es imposible superar el desfase entre la aspiración y la realidad; tal vez, la construcción de identidades novedosas en un mundo de fuerzas y amenazas, apremie el surgimiento de una nueva socialidad como lugar de encuentro de sensibilidades e interpretación de la crisis civilizatoria contemporánea. Ello obliga a repensar el devenir de la intolerancia, la admisión del conflicto frente a la solución, y la duda ante decisiones arbitrarias que, entre otros argumentos, constituyen los retos del pluralismo asumido como apuesta ética para el convivir entre diferentes y para construir la paz. 


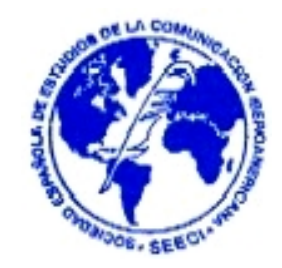

De hecho, el ejercicio del pensamiento único revela una resistencia a admitir las mutaciones de la vida cotidiana en el encuentro/desencuentro de sujetos, voces, creencias, valores, sentimientos y discrepancias, que bosquejan la pertenencia a una cultura y subcultura, donde múltiples experiencias, muchas veces contradictorias, pueden ser un vínculo para hacer dialogar distintas visiones del mundo.

Este compromiso

"abre enormes posibilidades para el ejercicio democrático, para el
intercambio de ideas, para la construcción de consensos y para
aprender a tramitar productivamente los disensos: todas ellas,
instancias formadoras de una convivencia más plena, de una
ciudadanía más compleja" (R. Gurevich. 2005: 27).

Cabe anotar que una cultura de paz se funda, por una parte, en el conocimiento crítico de la realidad social que tiene un potencial ético para desentrañar los discursos contradictorios y las prácticas incoherentes, tanto públicas como individuales; y por otra, se basa en una relación vinculante entre las ideas y la participación ciudadana.

Por esto, sin un acuerdo sobre el porvenir de la sociedad reinventada día a día, momento a momento, la ciudadanía intercultural seguirá siendo mera aspiración donde cada quien asume la postura que más le conviene, cada uno con sus intereses, cada uno con miradas opuestas, cada uno con aspiraciones interferidas por los grupos que imponen las reglas de acceso al poder. En este panorama no puede tener cabida la paz como proyecto colectivo.

Como vemos, el problema de la ciudadanía intercultural y la construcción de la paz en valores éticos es una cuestión de fondo que exige desentrañar, en el plano teórico y empírico, los mensajes implícitos en los discursos, descodificar las concepciones del mundo, las prácticas sociales y las ideologías, así como los conflictos subyacentes en los 


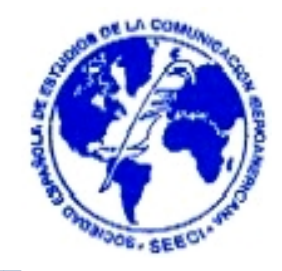

procesos históricos; además, no dudamos que le atañe también la interpretación de la memoria colectiva que constituye un sustento de la formación ciudadana.

Arribamos a la conclusión de que la ciudadanía no es sólo una categoría de análisis, sino una responsabilidad que reclama la construcción de un proyecto común para la vida democrática en tolerancia; ella, tiene un valor particular como formadora de ciudadanos que aspiran a vivir en paz; no me refiero a la paz utópica sino a la paz real que pretende una mejor calidad de vida material, espiritual y emocional, enmarcada en los valores de la diversidad social y en el pluralismo cultural y político.

\section{Bibliografía}

ARANGUREN, C.(2004): "Enseñanza de la historia, ciudadanía y pensamiento crítico" en Memorias de las V Jornadas de Investigación Humanística y Educativa. (Resúmenes). UCV. Caracas.

ARANGUREN, C.(2006): "Ciudadanía intercultural en tiempo de crisis" en Actas del XII Encuentro de Latinoamericanistas Españoles. Santander, España.

CORTINA, A.(1997): Ciudadanos del mundo. Hacia una teoría de la ciudadanía. 1a edición. Alianza. Madrid.

DUBY, G. (1996): Año 1000, año 2000. La huella de nuestros miedos. 1a edición. Editorial Andrés Bello. Santiago de Chile.

FOLLARI, R. (2000): Epistemología y sociedad. Acerca del debate contemporáneo. Homo Sapiens Ediciones. Santa Fe, Argentina. 


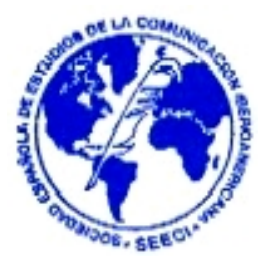

GIROUX, H y FLECHA, R. (1992): Igualdad educativa y diferencia cultural. 1a edición. El Roure. Barcelona.

GONZÁLEZ, S.(2005): La ciudad venezolana. Una interpretación de su espacio y sentido en la convivencia nacional. Fundación para la cultura urbana. Taller de Gráficas Lauki. Caracas.

GUREVICH, R. (2005): Sociedades y territorios en tiempos contemporáneos. 1a edición. Fondo de Cultura Económica. México.

KLOR DE ALBA, J. (1997): "El derecho a la diferencia: límites y retos" en GUTIÉRREZ, M. (compl). Identidades étnicas. Diálogos amerindios. 1a edición. Casa de América. Madrid.

MARTIN BARBERO, J. (2005): "Nuevos regímenes de visualidad y des-centramientos educativos" en Revista de Educación, № 338. Madrid.

NARANJO GIRON, GLORIA y otros. (2001): Ciudad y ciudadanía bajo la lente del conflicto urbano. 1aㅡ edición. Corporación Región. Medellín-Colombia.

SAN MARTIN, V. (2003): "Educación y ciudadanía en América Latina: sugerencias para el análisis y comprensión" en Revista de Educación, Número extraordinario. Madrid.

VÁSQUEZ, F. (2001): La memoria como acción social. Paidós. Barcelona. 